\title{
Gambaran Pelaksanaan Pelatihan Hypnoparenting untuk Mengatasi Masalah Perkembangan Anak Balita
}

\author{
Heny Noor Wijayanti ${ }^{1}$, Yana Luthfiyati ${ }^{2}$, Nabila Apriliani ${ }^{3}$ \\ Email: henywijayanti@respati.ac.id \\ ${ }^{1,2}$ Dosen Prodi DIII Kebidanan Fakultas Ilmu Kesehatan, Universitas Respati Yogyakarta \\ Mahasiswa Prodi DIII Kebidanan Fakultas Ilmu Kesehatan, Universitas Respati Yogyakarta, \\ Indonesia
}

\begin{abstract}
Abstrak
Latar Belakang : Pada masa balita terjadi proses pertumbuhan dan perkembangan yang sangat pesat baik pertumbuhan fisik, psikomotor, mental maupun social.Masa lima tahun pertama kehidupan merupakan periode masa emas terhadap lingkungan dan akan menjadi dasar kualitas generasi penerus bangsa. Permasalahan anak hampir 90\% disebabkan oleh kesalahan atau ketidaktahuan orangtua akan cara komunikasi dan penyampaian nilai yang baik terhadap sang anak. Tehnik hypnoparenting ini cara yang dapat orang tua lakukan dalam mengatasi berbagai macam masalah yang dialami anak. Tujuan : kegiatan ini adalah menerapkan pola asuh yang baik dengan hypnoparenting sehingga perkembangan anak menjadi lebih baik lagi. Metode : pelaksanaan kegiatan ini terdiri dari 2 tahapan yaitu pelatihan tentang hypnoparenting, dan evaluasi penerapan praktik hypnoparenting oleh orang tua anak. Hasil Pengabdian : hasil awal saat diberikan kuesioner tentang hypnoparenting sebagian responden belum pernah tahu tentanghypnoparenting tersebut ada 7 orang (70\%), orangtua antusias dalam pelatihan dan penerapan hypnoparenting. Kesimpulan : orang tua bisa mempraktekkan ke anaknya dalam pemberian sugesti yang positif sehingga perkembangan anak ada perubahan yang semakin baik.
\end{abstract}

Kata Kunci: hypnoparenting; anak balita.

\begin{abstract}
Background: During the toddler years, there is a very rapid growth and development process, both physical, psychomotor, mental and social growth. The first five years of life are a golden period for the environment and will be the basis for the nation's future generations. Almost $90 \%$ of children's problems are caused by parents' mistakes or ignorance of how to communicate and convey good values to the child. Hypnoparenting techniques are ways that parents can do in overcoming various kinds of problems that make children. Purpose: this activity is to apply good parenting with hypnoparenting so that children's development can be even better. Methods: the implementation of the activity consists of 2 stages of training on hypnoparenting, and evaluation of hypnoparenting practices by the child's parents. Results of Community Service: the initial results were given a questionnaire about hypnoparenting, some of the respondents who had never known about hypnoparenting were 7 people $(70 \%)$, parents who were enthusiastic in the training and application of hypnoparenting. Conclusion: parents can practice giving their children positive suggestions so that children's development is getting better.
\end{abstract}

Keywords: hypnoparenting; kids under five. 


\section{Pendahuluan}

Pada masa balita terjadi proses pertumbuhan dan perkembangan yang sangat pesat baik pertumbuhan fisik, psikomotor, mental maupun social. Pola asuh menjadi faktor risiko yang dapat mempengaruhi tumbuh kembang anak. Pola asuh dan sikap orang tua dapat mempengaruhi perkembangan anak usia 1-3 tahun. Peranan orang tua sangat penting terhadap asuhan kesehatan anak terutama ibu. Ibu adalah orang yang paling dekat dengan anak sekaligus sebagai pengatur ketersediaan makanan bagi keluarganya. Peran ibu dalam asupan makanan bagi anaknya berhubungan dengan tingkat pendidikan ibu, jenis pekerjaan ibu, tingkat pendapatan keluarga dan tingkat pengetahuan ibu tentang gizi.

Para orangtua dapat memberikan pembinaan atau arahan kepada anak-anaknya tanpa menggunakan paksaan yang akan dilaksanakan oleh anak dengan kesadaran penuh. Karena dalam kehidupan sehari-hari sering orangtua dengan segala wewenangnya, memerintahkan anaknya dengan berbagai kata ancaman atau dengan umpatan yang akan menyebabkan rekaman buruk bagi diri anak. Sebagian orangtua mungkin ada yang menyerah dengan keadaan anak-anaknya dalam keadaan buruk. $^{2}$

Kemampuan orang tua untuk mendeteksi tumbuh kembang anak dipengaruhi oleh tingkat pengetahuan dan tingkat pendidikan. Namun, penelitian lain yang menganalisis pengaruh tingkat pendidikan terhadap perkembangan sosial anak balita menyatakan bahwa pengaruh tingkat pendidikan tidak signifikan mempengaruhi perkembangan sosial anak balita. ${ }^{3}$ Untuk itu perlu upaya meningkatkan pemahaman orang tua dalam pola asuh anak, salah satunya yang dilakukan dengan meningkatkan peran orangtua dalam pemantauan pertumbuhan dan pemberian makanan bayi dan anak melalui pelatihan hypnoparenting.

Hypnoparenting merupakan salah satupembinaan anak dengan memperhatikan pengaruh hypnosis dengan rekaman postifatau sugeti pada anak pada jiwa bawahsadarnya. ${ }^{4} \quad$ Dengan Hypnoparenting orangtua akan lebihmudah berkomunikasi dengan anak. Menurut ${ }^{5}$ dengan Hypnoparenting bisa terjadi perubahan perilaku, perubahan kedisplinan waktu, perubahan perilaku ketika bermainpada anak sertabertambahnya wawasan oarangtua tentang pembelajaran hypnoparenting.

\section{Metode}

Metode yang digunakan untuk menyelesaikan permasalahan mitra yaitu dengan memberikan pelatihan tentang Hypnoparenting. Tahapan dalam kegiatan ini adalah sebagai berikut : yaitu pelatihan tentang hypnoparenting, dan evaluasi penerapan hypnoparenting oleh orang tua anak. Dilakukan secara online melalui google meet dengan responden ibu yang mempunyai balita dengan masalah perkembangan di wilayah Puskesmas Depok 2.

\section{Hasil dan Pembahasan}

Karakteristik Responden

Responden pada penelitian ini berjumlah 10 anak balita mengalami gangguan perkembangan dapat dilihat pada tabel 1 . 
Tabel 1. Karakteristik Balita dan Ibu

\begin{tabular}{ccc}
\hline & $\begin{array}{c}\text { Jumlah } \\
(\mathbf{N})\end{array}$ & $\begin{array}{c}\text { Persentase } \\
(\%)\end{array}$ \\
\hline Jenis Kelamin & & \\
$-\quad$ Laki-laki & 5 & 50 \\
$-\quad$ Perempuan & 5 & 50 \\
\hline Umur & 5 & 50 \\
$-\quad<$ sd 2 tahun & 5 & 50 \\
$-\quad$ 3 sd 5 tahun & 3 & 30 \\
\hline Tingkat Pendidikan Ibu & 5 & 50 \\
$-\quad$ Pendidikan Tinggi & 2 & 20 \\
$-\quad$ Pendidikan Menengah & & 30 \\
$-\quad$ Pendidikan Dasar & 3 & 70 \\
\hline Status Pekerjaan & 7 & \\
$-\quad$ Bekerja & Tidak Bekerja &
\end{tabular}

Dari tabel di atas dapat dilihat karakteristik responden anak balita yang berjenis kelamin perempuan ada $5(50 \%)$ dan laki-laki ada 5 (50\%), umur balita diantara $<1-2$ tahun dan 3-5 tahun sama-sama banyak antara 5 (50\%). Kemudian tingkat pendidikan ibu sebagian merupakan berpendidikan menengah $5(50 \%)$, tingkat pendidikan tinggi ada $3(30 \%)$ dan yang berpendidikan dasar ada $2(20 \%)$. Dengan tingkat pendidikan tersebut status pekerjaan ibu sebagian besar tidak bekerja ada 7 (70\%) dan yang bekerja $3(30 \%)$.

Pola asuh berarti pendidikan, sedangkan pendidikan adalah bimbingan secara sadar oleh pendidik terhadap perkembangan jasmani dan rohani anak didik menuju terbentuknya kepribadian yang utama. Pola asuh adalah suatu keseluruan interaksi orangtua dan anak, dimana orangtua memberikan dorongan, bagi anak untuk mengubah tingkah laku, pengetahuan dan nilai-nilai yang dianggap tepat bagi orang tua agar anak bisa mandiri tumbuh sehat serta berkembang secara optimal, memiliki rasa percaya diri,rasa ingin tahu, bersahabat dan berorientasi untuk sukses. ${ }^{7}$
Penyuluhan Hypnoparenting dapat meningkatkan pengetahuan dan keterampilan tentang hypnoparenting dalam pola asuh. Semakin tinggi pengetahuan orang tua tentang hal tersebut maka pola asuh untuk perkembangan anak akan semakin baik. Apalagi dilihat dari tingkat pendidikan orang tua yang sebagian berpendidikan menengah. ${ }^{8}$

\section{Kesimpulan}

Ketercapaian dalam kegiatan pengabdian masyarakat yang dilakukan oleh tim sudah sesuai dengan yang direncanakan. Metode yang digunakan adalah pemberian pelatihan Hypnoparenting, pendampingan dan evaluasi penerapan Hypnoparenting dirasa tepat sebagai solusi untuk menyelesaikan permasalahan mitra. Hasil dari kegiatan pengabdian ini adalah Hypnoparenting dapat diterapkan dan bias merubah sikap dan perilaku anak. Kegiatan ini diharapkan dapat bermanfaat bagi para orangtua anak, sehingga kedepannya dapat berdampak positif bagi perkembangan anak 


\section{Daftar Pustaka}

[1]. Khomsan, Pengantar Pangan dan Gizi. Cetakan-1. Jakarta: Penebar Swadaya, 2015.

[2]. Anshor, Ulfah Maria dan Abdullah Ghalib, Parenting With Love: Panduan Islami Mendidik Anak Penuh Cinta dan Kasih Sayang. Bandung: PT Mizan Pustaka, 2015.

[3]. Sutiyono, A, Dahsyatnya Hypnoparenting. Jakarta: Penebar Plus, 2010.

[4]. Santioso, Lucy, L. 5 Menit Menguasai Hypnoparenting. Jakarta : Penebar Plus, 2012.

[5]. Megawati, P. (2015). Perbedaan PerilakuAnak dengan pembelajaran HypnoParenting dan Non Hypnoparentingpada siswa TK Pertiwi bojonegoro Tahun Ajaran 2013/2014, Fakultas Ilmu Pendidkan UM (Skripsi).

[6]. Arikunto, Suharsimi. Prosedur Penelitian Suatu Pendekatan Praktik. Jakarta : Rineka Cipta, 2010.

[7]. Tridonanto, Mengembangkan Pola Asuh Demokratis. Jakarta: PT ElexMedia Kompotindo, 2014.

[8]. Munjinah Annif, Hidayah Nur. Optimalisasi Pola Asuh Dengan Menggunakan Hypnorarenting di Wonokromo Surabaya. Jurnal Unnusa 2018. [Online]. https://journal2.unusa.ac.id/ind ex.php/CDJ/article/view/718. 